\title{
Co-uptake of atrazine and mercury by rice seedlings from water
}

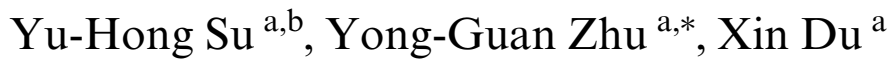 \\ ${ }^{a}$ Research Center for Eco-environmental Sciences, Chinese Academy of Sciences, Beijing 100085, China \\ ${ }^{\mathrm{b}}$ Chemistry Department, Xinjiang University, Urumqi 830046, China
}

Received 24 January 2005; accepted 15 March 2005

Available online 20 April 2005

\begin{abstract}
The uptake of atrazine (ATR) by rice seedlings (Oryza sativa L.) from nutrient solution was investigated in the presence and absence of $\mathrm{Hg}^{2+}$ over a period of $96 \mathrm{~h}$. Either ATR or $\mathrm{Hg}^{2+}$ was found phytotoxic to rice seedlings, as they inhibited the seedling growth. The seedlings showed about $50 \%$ biomass reduction when exposed to $1.0 \mathrm{mg} / \mathrm{L} \mathrm{Hg}^{2+}$ alone in nutrient solution, and about $80 \%$ reduction when exposed to $12.0 \mathrm{mg} / \mathrm{L}$ ATR alone. Observed ATR and $\mathrm{Hg}^{2+}$ levels (in $\mathrm{mg} / \mathrm{kg}$ ) in seedlings are not related to biomass changes. When either ATR or $\mathrm{Hg}^{2+}$ was applied, the concentrations in seedlings increased largely in proportion to those in nutrient solution. The presence of $\mathrm{Hg}^{2+}$ at 0.1 and $1.0 \mathrm{mg} / \mathrm{L}$ in solution caused a small-to-moderate decline in ATR uptake by the seedlings, the effect being largely independent of the ATR concentration in nutrient solution (at 6.0 and $12.0 \mathrm{mg} / \mathrm{L}$ ). The presence of ATR (at 6.0 and $12.0 \mathrm{mg} / \mathrm{L}$ ) in the nutrient solution led to small-to-moderate irregular changes in the $\mathrm{Hg}^{2+}$ concentrations in rice seedlings. The overall results showed that there was no significant interdependence between the uptakes of ATR and $\mathrm{Hg}^{2+}$ by rice seedlings, which is in contrast to the enhanced ATR uptake noticed earlier with $\mathrm{Pb}^{2+}$ ion. Plant uptake of non-ionic organic compounds, such as ATR may be partly through water channels on the plasma membranes of plant cells.
\end{abstract}

(c) 2005 Elsevier Inc. All rights reserved.

Keywords: Atrazine; Mercury; Rice seedlings; Uptake; Contamination

\section{Introduction}

Atrazine (ATR) is one of the most extensively applied herbicides in agriculture, and its residue

\footnotetext{
* Corresponding author. Fax: +861062923563.

E-mail address: ygzhu@mail.rcees.ac.cn (Y.-G. Zhu).
}

has spread widely across soils, surface water, and groundwater [1-6]. The phytotoxicity of atrazine on plants has been extensively studied [6-8]. Although banned in some countries (e.g., Germany), ATR remains as one of the most frequently detected environmental contaminants today [5]. In soils and groundwater, the atrazine level may reach several parts per million [9]. In 
China, ATR applied to rotation fields contaminates crops (e.g., rice plants), as crop seedlings accumulate atrazine residue from soil-water solution [10].

Previously, we have studied the uptake of ATR by rice seedlings from nutrient solution in the presence and absence of coexisting organic and metalion species [11]. It was found that the uptake of ATR and coexisting organic compounds by rice seedlings (e.g., chlorophenol and dichlorophenol) is largely unaffected by coexisting compounds [12] and appears to proceed essentially by passive (i.e., partition) mechanism, as evaluated by a partitionlimited model [13]. By contrast, the ATR uptake is enhanced by coexisting $\mathrm{Cd}^{2+}$ or $\mathrm{Pb}^{2+}$ ion [11] because of the ATR-ion binding [14,15]. Thus, the ATR uptake by plants in the presence of metal ions might become very complicated because of its potential metal-binding capability in addition to its passive-uptake process. In view of the occurrence of various metal ions in natural systems, it is vital to examine the impacts of different metal ions on the ATR uptake by plants.

Mercury is a toxic metal widely dispersed into the environment and is known to accumulate into the living organisms. Most important emissions of mercury originate from mining and smelting copper and zinc, burning of coal, mercury production and abatement processes, including waste incineration, with the emitted amount increasing rapidly in some nations [16]. Coal-fired power plants are the biggest source of mercury emissions into the atmosphere. During its atmospheric transport, the emitted $\mathrm{Hg}$ could fall back onto the earth surface through wet and dry deposition. It is found that more than $90 \%$ of $\mathrm{Hg}$ resides in terrestrial ecosystems $[17,18]$ in which soils are the biggest $\mathrm{Hg}$ recipient. Soil contamination with $\mathrm{Hg}$ is widespread in China, resulting primarily from irrigation of sewage water (e.g., in the suburbs of Beijing and Tianjing Municipalities) and $\mathrm{Hg}$-mining activities (e.g., in Guizhou Province, southwest China) [19], the levels of $\mathrm{Hg}$ found in a survey of Chinese soils range from 0.001 to $45.9 \mathrm{mg} / \mathrm{kg}$, with an average of $0.038 \mathrm{mg} / \mathrm{kg}$ [20]. It is estimated that emission of $\mathrm{Hg}$ from Guizhou Province itself to the atmosphere accounts for about $12 \%$ of the world's anthropogenic $\mathrm{Hg}$ emissions. The highest $\mathrm{Hg}$ level in rice grains in Guizhou reached $569 \mu \mathrm{g} / \mathrm{kg}$, of which $145 \mu \mathrm{g} / \mathrm{kg}$ was in methylmercury form [19]. In natural water, the ionic $\mathrm{Hg}^{2+}$ is often the prevailing mercury form.

Whereas $\mathrm{Hg}^{2+}$ is not recognized as an active metal to bind ATR [14,15], it is known to inhibit water uptake via aquaporins on plasma membranes in higher plants [21]. Considering the plant's passive uptake of organic compounds from external water [13], we hypothesize that $\mathrm{Hg}^{2+}$ in external water may inhibit the uptake of ATR, if it significantly inhibits the water flow. The aim of this study is therefore to test if ATR is taken up at least partly by rice seedlings passively through aquaporins on plasma membrane. This study is also intended to broaden the scope of the effect of metal ions on ATR uptake by rice seedlings by extending the earlier work on the influences of $\mathrm{Cd}^{2+}$ and $\mathrm{Pb}^{2+}$ ions on the ATR uptake by the same seedlings.

\section{Materials and methods}

\subsection{Preparation of rice seedlings}

Rice seeds (Oryza sativa cv Giyou-1) were disinfected in $30 \% \mathrm{H}_{2} \mathrm{O}_{2}$ (w:w) solution for $10 \mathrm{~min}$, followed by thorough washing with de-ionized water. The seeds were germinated in moist perlite. After 3 weeks, uniform seedlings were selected and transplanted to $\mathrm{PVC}$ pots $(7.5 \mathrm{~cm}$ diameter and $14 \mathrm{~cm}$ high, one plant per pot) containing $500 \mathrm{ml}$ of a nutrient solution. The compositions of nutrient solutions were as follows: $1.7 \mathrm{mM}$ $\mathrm{NH}_{4} \mathrm{NO}_{3}, \quad 4.0 \mathrm{mM} \quad \mathrm{KH}_{2} \mathrm{PO}_{4}, \quad 0.7 \mathrm{mM} \quad \mathrm{K}_{2} \mathrm{SO}_{4}$, $1.3 \mathrm{mM} \mathrm{CaCl}_{2}, 0.5 \mathrm{mM} \mathrm{MgSO}$, $50.0 \mu \mathrm{M} \mathrm{Fe}$ (III)ethylenediaminetetraacetic acid (EDTA), $5.0 \mu \mathrm{M}$ $\mathrm{H}_{3} \mathrm{BO}_{4}, 0.5 \mu \mathrm{M} \mathrm{ZnSO}_{4}, 0.5 \mu \mathrm{M} \mathrm{CuSO}_{4}, 2.5 \mu \mathrm{M}$ $\mathrm{MnSO}_{4}, 0.2 \mu \mathrm{M} \mathrm{Na} \mathrm{MoO}_{4}$, and $0.1 \mu \mathrm{M} \mathrm{CoSO}_{4}$. The nutrient solution was a modification of Long Ashton Formula after Zhu et al. [22] with the pH maintained at 5.0 using $0.1 \mathrm{M} \mathrm{KOH}$ or $\mathrm{HCl}$ solution [23]. The nutrient solution was changed twice a week. The seedlings were allowed to grow in nutrient solution for three weeks before being used for uptake studies. 


\subsection{Treatments with atrazine and mercury}

Chemicals used for plant uptake, such as $\mathrm{HgCl}_{2}, \mathrm{NH}_{4} \mathrm{NO}_{3}, \mathrm{CaCl}_{2}$, were all of analytical grade; ATR was provided by Chem. Service. The purities of all chemicals are more than $98 \%$. In series- 1 experiments, the rice seedlings were exposed to nutrient solutions with different (initial) ATR concentrations at 0, 2.0, 4.0, 6.0, 8.0, and $12.0 \mathrm{mg} / \mathrm{L}$ without added $\mathrm{Hg}$. In series-2, seedlings were exposed to $\mathrm{Hg}^{2+}$, as $\mathrm{HgCl}_{2}$, at 0 , 0.1 , and $1.0 \mathrm{mg} / \mathrm{L}$ without ATR. In series-3, seedlings were exposed to mixtures of ATR and $\mathrm{Hg}$, with ATR at 6.0 and $12.0 \mathrm{mg} / \mathrm{L}$, and $\mathrm{Hg}^{2+}$ concentration kept at $0.1 \mathrm{mg} / \mathrm{L}$. In series-4, seedlings were exposed to mixtures of ATR and $\mathrm{Hg}$, with ATR at 6.0 and $12.0 \mathrm{mg} / \mathrm{L}$, while $\mathrm{Hg}^{2+}$ concentration at $1.0 \mathrm{mg} / \mathrm{L}$. In series- 1 and series-2, each treatment was conducted with four replicates; in series-3 and series-4, each treatment was conducted with eight replicates. The exposure periods for all these experiments were $96 \mathrm{~h}$. Nutrient solutions with prefixed ATR and/or $\mathrm{Hg}^{2+}$ levels were not replaced during the experimental period. The experiments were carried out in a controlled environment with a 14-h light period (260-350 $\left.\mu \mathrm{mol} \mathrm{m}^{-2} \mathrm{~s}^{-1}\right)$ and temperatures of $25^{\circ} \mathrm{C}$ day and $20^{\circ} \mathrm{C}$ night. The relative humidity was $70 \%$. The control seedlings at the end of the experiments were sectioned into roots and shoots, weighed, and parts of them then freezedried $\left(-45^{\circ} \mathrm{C}\right)$ to determine the respective plant water contents $\left(f_{\mathrm{pw}}\right)$ and organic-matter contents $\left(f_{\text {pom }}\right)$.

The nutrient solutions containing different levels of given contaminants were held by a series of identical PVC cylinders. The cylinder was fitted with a PVC septum $(7.5 \mathrm{~cm}$ in diameter and $0.5 \mathrm{~cm}$ in thickness) with a hole drilled at its center $(1.5 \mathrm{~cm}$ in diameter $)$, through which the plant shoots extended into outside air. The section of shoots passing through the septum hole was wrapped with sponge sheets to minimize the open space. This design prevented direct water evaporation from nutrient solution into the outside air when seedlings were in place and maintained full contacts of seedling roots with nutrient solutions.

\subsection{Analysis of mercury}

After plants were harvested, $\mathrm{Hg}^{2+}$ (and ATR, if present) in solution was analyzed. The plant roots were washed with deionized water and blotted dry. The plants were then separated into shoots and roots and the respective fresh weights were recorded immediately. The shoots and roots from series- 2 and parts of series- 3 and series- 4 experiments were freeze-dried at $-45^{\circ} \mathrm{C}$ for $48 \mathrm{~h}$ and the dry weights were recorded. The dried plant material was ground and a weighed amount of sample was placed into clean, dry Teflon tubes for digestion $(100 \mathrm{ml})(\mathrm{CEM}$ digestion tubes). Concentrated $\mathrm{HNO}_{3}(5 \mathrm{ml})$ was added. The tubes were placed on a microwave-accelerated reaction system (Mars5, CEM microwave Technology, USA). The sample digestion was conducted with $15 \mathrm{~min}$ ramping (at $10^{\circ} \mathrm{C} / \mathrm{min}$ ) to $160^{\circ} \mathrm{C}$, with a holding at this temperature for $15 \mathrm{~min}$. After digestion, the solutions were cooled, diluted to $50 \mathrm{ml}$ with ultra-pure water (Easy-pure, Dubugue, Iowa, USA) and transferred into acidwashed plastic bottles. Concentrations of $\mathrm{Hg}$ in acid digests were quantified with an atomic fluorescence spectrometer (AFS-2202E, made in China) [24].

\subsection{Analysis of atrazine}

The seedling samples were first cut to separate them into roots and shoots. The cut shoots and roots were rinsed with distilled water four times to remove residual ATR on seedling surfaces, wiped with tissue paper, and immediately weighed. The samples were then homogenized using a mortar and pestle, and then extracted using an ultrasonic crusher machine with $40 \mathrm{ml}$ of mixed methanol and water $(1: 1, \mathrm{v}: \mathrm{v})$. The liquid phase was filtrated and collected. The samples were then extracted three times with $10 \mathrm{ml}$ of fresh mixed solvents. The liquid portions from all extractions were combined and extracted with $20 \mathrm{ml}$ of mixed petroleum ether and dichloromethane (6.5:3.5, v:v). Supernatants of the mixed-solvent phase were eluted through anhydrous $\mathrm{Na}_{2} \mathrm{SO}_{4}$ columns and collected. This procedure was repeated four times. The eluates were combined, concentrated into a small volume (1$2 \mathrm{ml}$ ) using a rotary evaporator (Senco, China) with a gentle stream of dry nitrogen, solvated 
again with $30 \mathrm{ml}$ petroleum ether, and extracted three times with $20 \mathrm{ml}$ acetonitrile. The acetonitrile fractions were combined, concentrated, and evaporated off. The residues were solvated with petroleum ether and cleaned with a Florisil column. The concentrations of ATR in extracts were analyzed with an Agilent 6820 gas chromatograph with a ${ }^{63} \mathrm{Ni}$ electron capture detector (ECD) using a HP-5 capillary column $(0.32 \mathrm{~mm} \times 30 \mathrm{~m}, 0.25 \mu \mathrm{m}$ film thickness). Peak areas of ATR were quantified with external standards for quantifying ATR concentrations. The average recoveries of ATR in controls were $90.3 \pm 6.4 \%(n=5)$ for the plant samples.

\subsection{Data analysis}

Analysis of variance (ANOVA) was performed using Genstat for Windows on a personal computer (NAG Ltd, England). Two-way analysis of variance was carried out on ATR and mercury uptake data.

\section{Results and discussion}

\subsection{Plant biomass}

The observed biomasses of both roots and shoots showed large decreases when the seedlings were exposed to increasing concentrations of either ATR or $\mathrm{Hg}^{2+}$ alone in growth solution as compared to the control (Table 1). At fixed concentrations of ATR in nutrient solution ( 6.0 or $12.0 \mathrm{mg}$ / $\mathrm{L})$, the respective biomasses are found to increase to a small-to-moderate extent when the $\mathrm{Hg}^{2+}$ level in solution increases from 0.1 to $1.0 \mathrm{mg} / \mathrm{L}$. However, with fixed concentrations of $\mathrm{Hg}^{2+}$ in solution, changes in biomass with varied ATR concentrations (from 6.0 to $12.0 \mathrm{mg} / \mathrm{L}$ ) are generally small and not all consistent in trend. Overall, the data suggested that although the added $\mathrm{Hg}^{2+}$ level may affect the seedling growth to some extent, the seedling growth is mediated mainly by the ATR phytotoxicity, i.e., there appears to be no measurable ATR- $\mathrm{Hg}^{2+}$ complexation to significantly attenuate the ATR toxicity.

\subsection{Atrazine uptake}

Earlier studies showed evidence that the plant uptake of most non-ionic organic compounds from external water occurs essentially by passive process (i.e., partition) $[13,25,26]$. Without the addition of $\mathrm{Hg}^{2+}$, the observed ATR concentrations in roots and shoots of rice seedlings are significantly higher than in external nutrient solution after the 96-h exposure. Close linear relations exist between ATR concentrations in roots/shoots and nutrient solution, as shown in Fig. 1. The ATR concentrations

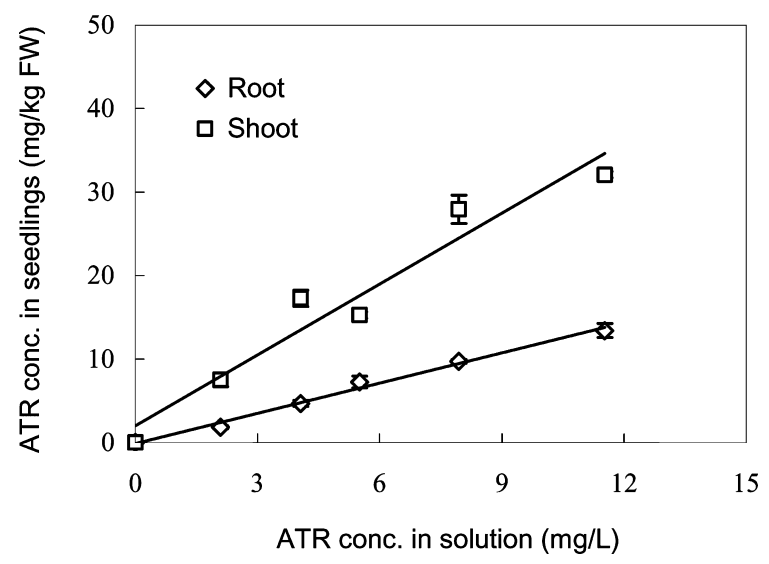

Fig. 1. Atrazine uptake by rice seedlings from nutrient solution without $\mathrm{Hg}$ added. Each point is the mean of four replicates. Error bars represent the standard errors (SE).

\section{Table 1}

Biomass (g dry matter) of rice seedlings exposed to various concentrations of atrazine (ATR, $\mathrm{mg} / \mathrm{L})$ and $\mathrm{mercury}\left(\mathrm{Hg}{ }^{2+}, \mathrm{mg} / \mathrm{L}\right)$ in nutrient solution (mean $\pm \mathrm{SE}, n=4)$

\begin{tabular}{|c|c|c|c|c|c|c|}
\hline \multirow[t]{3}{*}{ ATR concentrations } & \multicolumn{6}{|c|}{$\mathrm{Hg}$ concentrations } \\
\hline & \multicolumn{3}{|c|}{ Root biomass } & \multicolumn{3}{|c|}{ Shoot biomass } \\
\hline & 0.0 & 0.1 & 1.0 & 0.0 & 0.1 & 1.0 \\
\hline 0.0 & $0.20 \pm 0.02$ & $0.13 \pm 0.01$ & $0.10 \pm 0.01$ & $0.92 \pm 0.04$ & $0.69 \pm 0.03$ & $0.51 \pm 0.05$ \\
\hline 6.0 & $0.05 \pm 0.01$ & $0.04 \pm 0.01$ & $0.07 \pm 0.01$ & $0.27 \pm 0.01$ & $0.23 \pm 0.01$ & $0.32 \pm 0.02$ \\
\hline 12.0 & $0.04 \pm 0.01$ & $0.05 \pm 0.01$ & $0.06 \pm 0.01$ & $0.17 \pm 0.01$ & $0.24 \pm 0.01$ & $0.26 \pm 0.02$ \\
\hline
\end{tabular}


are higher in shoots than in roots. This difference is consistent with the presumed ATR association with certain active metal ions (e.g., $\mathrm{Mg}^{2+}$ ) in shoots (leaves) that support plant photosynthesis [11]. While the different ATR concentrations in nutrient solution $(6.0$ and $12.0 \mathrm{mg} / \mathrm{L})$ reduced the biomass of rice seedlings to different extents (Table 1), the fact that the linear concentration relationship exists between concentrations in plant tissues and nutrient solutions (Fig. 1) indicates that the plant ATR concentration is largely independent of the biomass. This effect suggests that the ATR concentration in plants reaches a steady-state level with respect to the external nutrient solution concentration.

ATR is known to bind with certain metal ions (e.g., $\mathrm{Mg}^{2+}, \mathrm{Cd}^{2+}$, and $\mathrm{Pb}^{2+}$ ) [14,15], and is thus able to interrupt the plant photosynthesis by acting as an electron acceptor in the electron-transfer process. Therefore, the uptake of ATR by plant shoots may be enhanced by some active metal ions in plant leaves in addition to its passive uptake by the plant organic matter [27]. However, in the present experiment in the ATR $-\mathrm{Hg}^{2+}$ mixture systems, the presence of $\mathrm{Hg}^{2+}$ at 0.1 and $1.0 \mathrm{mg} / \mathrm{L}$ in solution significantly reduced the ATR levels in both roots and shoots, especially the latter (Fig. 2). The observed ATR concentrations in the seedlings with added $\mathrm{Hg}^{2+}$ show no definitive relations with the corresponding biomasses. As noted, the effect of $\mathrm{Hg}^{2+}$ on tissue ATR concentrations increased with increasing $\mathrm{Hg}^{2+}$ concentration (from 0.1 to $1.0 \mathrm{mg}$ / L). The essentially linear relations between the ATR concentrations in seedlings and nutrient solution, illustrated by Fig. 2, indicate that the reductions in ATR concentrations in both roots and shoots are practically independent of the ATR concentrations in solution. The reducing effect of $\mathrm{Hg}^{2+}$ on ATR uptake is a sharp contrast to the enhancing effect of either $\mathrm{Cd}^{2+}$ or $\mathrm{Pb}^{2+}$ on ATR uptake observed earlier [11], although the latter studies were conducted over a much longer exposure period (4 weeks). The reduced ATR uptake with $\mathrm{Hg}^{2+}$, which is independent of the ATR concentrations in water, suggests that the ATR $-\mathrm{Hg}^{2+}$ binding to form a non-extractable complex is not a likely cause, since this formation under a fixed $\mathrm{Hg}^{2+}$ level should show a dependence on the ATR
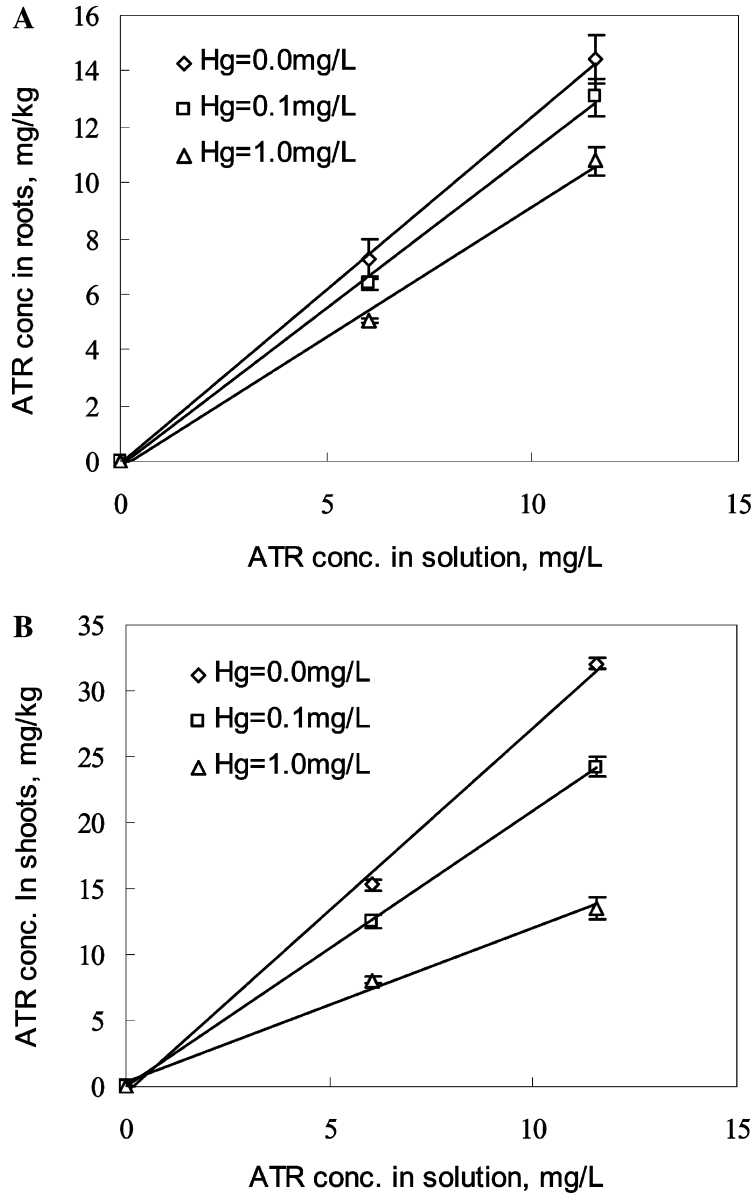

Fig. 2. Atrazine uptake by rice seedlings from nutrient solution with and without added $\mathrm{Hg}$. Each point is the mean of four replicates. Error bars represent the standard errors (SE).

concentrations in nutrient solution and plant tissues. Instead, it appears that $\mathrm{Hg}^{2+}$ inhibits the ATR uptake by somehow blocking the transport path of ATR within the plants, considering that the effect is greater at higher $\mathrm{Hg}^{2+}$ level and more significant for distant shoots than for directly exposed roots. Given the fact that $\mathrm{Hg}^{2+}$ is an inhibitor of water channels on plasma membranes of plant cells [19], the reduction in ATR accumulation in plant tissues by $\mathrm{Hg}^{2+}$ in the external solution may indicate ATR is taken up at least partly via water channels However, further studies are warranted to clarify to what extent water channels contribute to the overall accumulation of nonionic organic compounds by higher plants. 
Table 2

$\mathrm{Hg}^{2+}$ concentrations ( $\mathrm{mg} \mathrm{kg}^{-1}$ fresh weight) in rice seedlings exposed to various concentrations of ATR (mg/L) and $\mathrm{Hg}{ }^{2+}(\mathrm{mg} / \mathrm{L})$ in nutrient solution (mean $\pm \mathrm{SE}, n=4$ )

\begin{tabular}{|c|c|c|c|c|c|c|}
\hline \multirow{3}{*}{$\begin{array}{l}\mathrm{Hg} \text { concentrations } \\
\text { in solution }\end{array}$} & \multicolumn{6}{|c|}{ ATR concentrations in solution } \\
\hline & \multicolumn{3}{|c|}{$\mathrm{Hg}$ concentrations in roots } & \multicolumn{3}{|c|}{$\mathrm{Hg}$ concentrations in shoots } \\
\hline & 0.0 & 6.0 & 12.0 & 0.0 & 6.0 & 12.0 \\
\hline 0.1 & $15.94 \pm 1.60$ & $33.29 \pm 2.24$ & $29.90 \pm 1.36$ & $1.71 \pm 0.11$ & $1.07 \pm 0.06$ & $1.51 \pm 0.09$ \\
\hline \multirow[t]{2}{*}{1.0} & $125.5 \pm 3.54$ & $119.2 \pm 5.22$ & $117.9 \pm 3.87$ & $14.77 \pm 1.38$ & $19.13 \pm 1.23$ & $24.64 \pm 3.36$ \\
\hline & \multicolumn{6}{|c|}{ Analysis of variance } \\
\hline $\mathrm{Hg}$ & & $* * *$ & & & $* * *$ & \\
\hline ATR & & NS & & & $*$ & \\
\hline $\mathrm{ATR} \times \mathrm{Hg}$ & & $* *$ & & & $*$ & \\
\hline
\end{tabular}

NS, not significant.

${ }^{*} P<0.05$.

** $P<0.01$.

*** $P<0.001$.

\subsection{Hg uptake}

Without ATR, the $\mathrm{Hg}^{2+}$ level in roots and shoots increased nearly proportionally with increasing $\mathrm{Hg}^{2+}$ levels in nutrient solution (see Table 2). In $\mathrm{Hg}^{2+}$-ATR mixture systems, the addition of ATR to solution with a fixed $\mathrm{Hg}^{2+}$ level produced small-to-moderate irregular changes in $\mathrm{Hg}^{2+}$ levels in roots and shoots. In these systems, the $\mathrm{Hg}^{2+}$ concentrations in rice seedlings bear no definitive relations to the corresponding seedling biomasses. Overall, the uptake of $\mathrm{Hg}^{2+}$ is not sensitively influenced by ATR in the solution.

Based on the combined results as discussed above, one may conclude that there is no significant binding between $\mathrm{Hg}^{2+}$ and ATR within the plant body, as a strong binding should be concentration dependent and likely lead to enhanced ATR and/or $\mathrm{Hg}^{2+}$ uptake by the seedlings. This is consistent with the literature that $\mathrm{Hg}^{2+}$ is not recognized as a strong binder for ATR. It appears that the reduced uptake of ATR caused by added $\mathrm{Hg}^{2+}$ is related to the blockage of ATR transport into the rice seedlings, possibly mediated by the reduced permeability of water channels on root cell membranes. Opposite to the present finding, our earlier study shows that if a metal ion (e.g., $\mathrm{Cd}^{2+}$ or $\mathrm{Pb}^{2+}$ ) binds strongly with ATR, both the uptakes of ATR and the metal ion by rice seedlings are enhanced. This indicates that the uptake of ATR in the presence of different coexisting metal ions may be very complex and unpredictable, depending on specific metal ions and other conditions involved. More future work is needed to delineate the complex effect of metal ions on ATR uptake by rice seedlings and other plant species.

\section{Acknowledgments}

This study was financially supported by the Ministry of Science and Technology (2002CB410808) and the Chinese Academy of Sciences (KZCX3-SW-431 and the Hundred Talent Program).

\section{References}

[1] D.A. Belluck, S.L. Benjamin, T. Dawson, Groundwater contamination by atrazine and its metabolites: risk assessment, policy, and legal implications, American Chemical Society. Ann. Proc. (1991) 254-273.

[2] T.E. McKone, K.T. Bogen, Predicting the uncertainties in risk assessment, Environ. Sci. Technol. 25 (1991) 1674 1681 .

[3] B.L. Finley, D.A. Mayhall, P.K. Scott, Development of a standard soil-to-skin adherence probability density function for use in Monte Carlo analysis of dermal exposure, Risk Anal. 14 (1994) 555-569.

[4] M.R. Burkart, D.W. Kolpin, Hydrologic and land-use factors associated with herbicides and nitrate in near-surface aquifers, J. Environ. Qual. 22 (1993) 646-656. 
[5] M. Gfrerer, T. Wenzl, X. Quan, B. Platzer, E. Lankmayr, Occurrence of triazines in surface and drinking water of Liaoning Province in Eastern China, J. Biochem. Biophys. Methods 53 (2002) 217-228.

[6] J.G. Gu, Y.Z. Fan, J.D. Gu, Biodegradability of atrazine, cyanazine and dicamba under methanogenic condition in three soils of China, Chemosphere 52 (2003) 15151521.

[7] R.H. Shimabukuoro, H.R. Swanson, W.C. Walsh, Glutathione conjugation: atrazine detoxication mechanism in corn, Plant Physiol. 46 (1970) 103-107.

[8] D.S. Frear, H.R. Swanson, Biosynthesis of $S$-(4-ethylamino-6-isopropylamino-2-s-traizine) glutathione: partial purification and properties of glutathione $S$-transferase from corn, Phytochemistry 9 (1970) 2123-2132.

[9] C. Wiegand, S. Pflugmacher, M. Giese, H. Frank, C. Steinberg, Uptake, toxicity, and effects on detoxification enzymes of atrazine and trifluoroacetate in embryos of zebrafish, Ecotoxicol. Environ. Safety 45 (2000) 122131.

[10] R.Z. Fan, Summarization of phytotoxicity of atrazine and the method of elimination, Pestic. Sci. Manag. 24 (2003) 20-23 (in Chinese).

[11] Y.H. Su, Y.G. Zhu, Influence of lead on atrazine uptake by rice (Oryza sativa L.) seedlings from nutrient solution, Environ. Sci. Pollut. Res. 12 (2005) 21-27.

[12] Y.H. Su, Y.G. Zhu, Bioconcentration of atrazine and chlorophenols into roots and shoots of rice seedlings. Environ. Pollut. (accepted).

[13] C.T. Chiou, G.Y. Sheng, M. Manes, A partition-limited model for the plant uptake of organic contaminants from soil and water, Environ. Sci. Technol. 35 (2001) 1437-1444.

[14] M. Martin, A. Hagege, J.P. Brunette, M. Leroy, Use of synergistic extraction for the study of atrazine/metal interactions, Anal. Chim. Acta 373 (1998) 161-165.

[15] Z. Meng, W.R. Carper, Effects of hydration on the molecular structure of metal ion-atrazine dimmer complexes: a MOPAC(PM3) study, J. Mol. Struct. (Theochem) 531 (2000) 89-98.

[16] E. Steinnes, Mercury, in: B.J. Alloway (Ed.), Heavy Metals in Soils, Wiley, New York, 1990, pp. 220-236.
[17] O. Lindqvist, K. Johansson, M. Aastrup, A. Andersson, L. Bringmark, G. Hovsenius, L. Håkanson, Å Iverfldt, M. Meili, B. Timm, Mercury in the Swedish environment, Water, Air, Soil Pollut. 55 (1991) 261.

[18] W.F. Fitzgerald, Is mercury increasing in the atmosphere? The need for an atmosphere mercury network (AMNET), Water, Air, Soil Pollut. 80 (1995) 245-254.

[19] M. Horvat, N. Nolde, V. Fajon, V. Jereb, M. Logar, S. Lojen, R. Jacimovic, I. Falnoga, Q. Liya, J. Faganeli, D. Drobne, Total mercury, methylmercury and selenium in mercury polluted areas in the province Guizhou, China, Sci. Total Environ. 304 (2003) 231-256.

[20] China National Environmental Monitoring Station (CNEMS): Background Elemental Concentrations of Chinese Soils. China Environmental Science Press, Beijing, 1990.

[21] W.H. Zhang, S.D. Tyerman, Inhibition of water channels by $\mathrm{HgCl}_{2}$ in intact wheat root cells, Plant Physiol. 120 (1999) 849-857.

[22] Y.G. Zhu, G. Shaw, A.F. Nisbet, B.T. Wilkins, Effect of external potassium on compartmentation and flux characteristics of radiocaesium in intact spring wheat roots, Ann. Botany 84 (1999) 644-659.

[23] C.L. Trostle, P.R. Bloom, D.L. Allan, HEDTA-nitrilotriacetic acid chelator-buffered nutrient solution for zinc deficiency evaluation in rice, Soil Sci. Soc. Am. J. 65 (2001) 385-390.

[24] X. Du, Y.G. Zhu, W.J. Liu, X.S. Zhao, Uptake of mercury $(\mathrm{Hg})$ by seedlings of rice (Oryza sativa L.) grown in solution culture and interactions with arsenate uptake. Environ. Exp. Botany. (2005, online).

[25] G.G. Briggs, R.H. Bromilow, A.A. Evans, Relationship between lipophilicity and root uptake and translocation of non-ionised chemicals by Barley, Pestic. Sci. 13 (1982) 495504.

[26] S. Trapp, Plant uptake and transport models for neutral and ionic chemicals, Environ. Sci. Pollut. Res. 11 (2004) 3339.

[27] J. Hirschberg, L. McIntosh, Molecular basis of herbicide resistance in Amaranthus hybridus, Science 222 (1983) 1346-1349. 